Revta brasil. Bot., São Paulo, V.23, n.3, p.291-304, set. 2000

\title{
Florística e fitossociologia de remanescentes de floresta estacional decidual em Piracicaba, São Paulo, Brasil
}

\author{
NATÁLIA MACEDO IVANAUSKAS ${ }^{1}$ e RICARDO RIBEIRO RODRIGUES ${ }^{2}$
}

(recebido em 20 de outubro de 1999; aceito em 5 de abril de 2000)

\begin{abstract}
Floristic and phytosociology of remnants of deciduous seasonal forest in Piracicaba, São Paulo State, Brazil). This study was conducted in two remnants of deciduous seasonal forest with 4 and 10 ha, in Piracicaba, São Paulo State, Brazil. This forest has peculiar abiotic characteristics, growing on inceptisol, with hydric deficit in the dry season and water excess in the wet season determining a peculiar flora and a physiognomy similar to the dry forests. A floristic survey was carried out in both remnants while a phytosociological was carried out in the 10 ha remnant, where the individuals with $\mathrm{PBH} \geq 15 \mathrm{~cm}$, present in 43 plots of $10 \mathrm{x} 10 \mathrm{~m}$, were recorded. One hundred and ten species, 86 genera and 42 families were registered. We found $20.7 \%$ of the species bearing spines, $31.0 \%$ of the 894 individuals registered had ramification at the soil level, and in the dominant stratum there were species that lose leaf turgescence (24.7\% of individuals), and deciduous (59.4\%), leafless (13.3\%), perenial (1.6\%) and semi-deciduous species (1.0\%). The families with the highest number of species were Leguminosae, Myrtaceae and Rutaceae. The most important species were Cereus hildmanianus, Eugenia florida, Eugenia uniflora, Pseudobombax grandiflorum and Sebastiania serrata. The Shannon's diversity index (H') was 3.0 nats/individuals and the eqüability (J) was 0.7 nats/indivíduos.
\end{abstract}

RESUMO - (Florística e fitossociologia de remanescentes de floresta estacional decidual em Piracicaba, São Paulo, Brasil). O estudo foi realizado em dois remanescentes de floresta estacional decidual de 4 e 10 ha, em Piracicaba, São Paulo, Brasil. Esta floresta tem características abióticas próprias, como solo litólico, estresse hídrico no período seco e excesso de água no período úmido, definindo uma flora particular e fisionomia semelhante a de florestas secas. O levantamento florístico foi realizado nos dois remanescentes e o fitossociológico naquele de 10 ha, onde foram amostrados os indivíduos com perímetro à altura do peito (PAP) $\geq 15 \mathrm{~cm}$ existentes em 43 parcelas de 10 x $10 \mathrm{~m}$. Foram registradas 110 espécies, 86 gêneros e 42 famílias. Do total de espécies, 20,7\% continham espinhos, $31,0 \%$ dos 894 indivíduos amostrados apresentaram-se perfilhados e, no estrato dominante, ocorreram espécies com perda de turgescência foliar (24,7\% dos indivíduos), decíduas $(59,4 \%)$, áfilas (13,3\%) perenes $(1,6 \%)$ e semidecíduas $(1,0 \%)$. As famílias de maior riqueza na fitossociologia foram Leguminosae, Myrtaceae e Rutaceae. As espécies de maior valor de importância foram Cereus hildmanianus, Eugenia florida, Eugenia uniflora, Pseudobombax grandiflorum e Sebastiania serrata. O índice de diversidade de Shannon (H') foi de 3,0 nats/indivíduos e a equabilidade (J) de 0,7 nats/indivíduos.

Key words - Deciduous seasonal forest, dry forest, floristic, phytosociology

\section{Introdução}

A denominação floresta estacional decidual (Veloso 1992) foi escolhida para designar remanescentes florestais existentes no município de Piracicaba, sempre associados a solos litólicos cascalhentos de origem calcária, alta fertilidade, baixa capacidade de retenção hídrica na estação seca e excesso de água na estação chuvosa, agravada pela condição topográfica, já que esses solos estão localizados em terras planas ou de pequena declividade, tornando a saturação hídrica mais pronunciada (Oliveira \& Prado 1989). Tais fatores

1. Universidade do Estado de Mato Grosso, campus de Nova Xavantina, Caixa Postal 8, 78690-000 Nova Xavantina, MT, Brasil.

2. Depto de Ciências Biológicas, Escola Superior de Agricultura "Luiz de Queiroz", Universidade de São Paulo, Caixa Postal 9, 13418-900 Piracicaba, SP, Brasil, Autor para correspondência: rrrodrig@ carpa.ciagri.usp.br. contribuem para a seletividade das espécies ocorrentes nesta formação, relacionada à adaptabilidade morfológica e fisiológica das mesmas, de maneira a resistir tanto à deficiência hídrica na estação seca como à saturação hídrica do solo no período úmido, mesmo que ambos eventos (estresse e saturação hídrica) ocorram por curtos períodos de tempo. Essa formação é de relevante importância por apresentar fisionomia e florística próprias, bem distinta das demais formações presentes sobre outros tipos de solos do município e da região, contribuindo para a biodiversidade remanescente.

Como adaptações fisiológicas e/ou morfológicas à deficiência hídrica estacional, as espécies presentes nessa formação apresentam armazenamento de água em partes da planta, deciduidade pronunciada (queda das folhas no período seco), órgãos para absorção da umidade atmosférica ou de chuvas, perda de turgescência foliar e outras. Mais complexas seriam as adaptações das espécies relacio- 
nadas à saturação hídrica do solo. Relativamente poucas espécies arbóreas tropicais desenvolveram mecanismos adaptativos que permitam a sua sobrevivência em condições anaeróbicas (Joly 1991).

Em trechos de terreno plano desta formação, há murunduns e canais superficiais não interligados e de pequena dimensão, definindo uma superfície irregular do terreno onde a água se acumula no período chuvoso e circula sem uma orientação definida. Nesta situação, as árvores se posicionam sobre os murunduns formados entre os canais, onde a influência da água do solo no período chuvoso é menor ou inexistente. Este microrrelevo assemelha-se ao encontrado em florestas paludosas (Ivanauskas et al. 1997, Toniato et al. 1998).

Em todo o Estado de São Paulo, a floresta estacional decidual ainda é muito pouco estudada. Como ocorre sempre associada a manchas de solos litólicos e cascalhentos, apresenta ocorrência naturalmente fragmentada. Como este tipo de solo não apresenta aptidão agrícola, ainda podem ser encontrados alguns remanescentes desta formação em Piracicaba e nos demais municípios do estado (Laranjal Paulista, Tietê, Brotas e outros). Mesmo assim, essas áreas merecem ações urgentes de preservação.

Recomendam-se pesquisas relacionadas aos mecanismos adaptativos e à fenologia das espécies que compõem os remanescentes desta formação, fornecendo dados que poderão contribuir significativamente para o entendimento das formações florestais brasileiras, e para o conhecimento da biodiversidade, já que apresentam particularidades florísticas pronunciadas.

Neste contexto, este trabalho procurou apresentar a estrutura e a composição florística de dois remanescentes de floresta estacional decidual, localizados na bacia do córrego da Laranja Azeda (região dos Godinhos) em Piracicaba, São Paulo.

\section{Material e métodos}

O estudo foi realizado no município de Piracicaba-SP, de clima tropical úmido, classificado pelo sistema de Koeppen como Cwa (Ometto 1981). Durante 1991, ano de maior intensidade de coleta de material florístico, a temperatura média oscilou entre $17,7{ }^{\circ} \mathrm{C}$ (julho) e $24,7{ }^{\circ} \mathrm{C}$ (dezembro) e a precipitação mensal variou entre 4,7 $\mathrm{mm}$ (agosto) e 431,9 $\mathrm{mm}$ (março), totalizando uma precipitação anual de 1493,5 mm (dados fornecidos pelo Departamento de Física e Meteorologia da ESALQ/USP). Há clara sazonalidade, havendo um período quente e chuvoso, coincidente com um fotoperíodo maior (aproximadamente de outubro a maio) e um período frio e seco, coincidente com um fotoperíodo menor (de abril a setembro) (Setzer 1966).

A área de estudo compreende dois remanescentes de floresta estacional decidual de 4 e 10 ha, localizados em área arrendada pela Usina Costa Pinto, no Bairro Godinhos (22 ${ }^{\circ} 39^{\prime}$ S e $47^{\circ} 39^{\prime}$ W). Os estudos florísticos foram realizados nos dois remanescentes e a locação de perfis e o levantamento fitossociológico foi realizado no remanescente de maior tamanho, que é também o mais preservado. Ambos os remanescentes situam-se numa área de relevo suave ondulado, a $554 \mathrm{~m}$ de altitude, sobre solo litólico cascalhento indiscriminado originário de sedimentos da formação Corumbataí (Oliveira \& Prado 1989).

O levantamento florístico teve início em março de 1991, coletando material fértil em caminhadas quinzenais nos dois remanescentes, durante o período de um ano.

Para o levantamento fitossociológico, foram locadas 43 parcelas de $10 \times 10$ m, mantendo-se uma distância fixa de $20 \mathrm{~m}$ entre parcelas, totalizando 0,4 ha. Foram registrados todos os indivíduos com PAP (perímetro à altura do peito) $\geq 15 \mathrm{~cm}$, exceto para os indivíduos que perfilharam acima do solo e abaixo da altura do peito $(1,30 \mathrm{~m})$. Para estes, foi adotado o seguinte critério: o indivíduo foi incluído quando pelo menos uma das ramificações obedecia ao critério de inclusão ( $\mathrm{PAP} \geq 15 \mathrm{~cm}$ ), sendo então anotado o PAP de todas as ramificações para o cálculo da área basal. Para cada indivíduo amostrado, foram anotados valores de PAP e altura (distância do ápice da copa ao solo, numa linha perpendicular a este), observações de campo e coletado material botânico para identificação.

O material botânico coletado no levantamento florístico e fitossociológico foi processado e identificado no Departamento de Ciências Biológicas da ESALQ/USP e, posteriormente, incorporado ao Herbário ESA, dessa mesma Instituição.

Os parâmetros fitossociológicos foram obtidos utilizando-se o programa FITOPAC (Shepherd 1994) e são aqueles descritos por Whittaker (1972) e Mueller-Dombois \& Ellemberg (1974).

Para a caracterização fisionômica do remanescente, foram elaborados três diagramas de perfil, seguindo a metodologia descrita por Richards (1964). Os perfis foram realizados em faixas de $30 \mathrm{~m}$ de comprimento e $10 \mathrm{~m}$ de largura, em três áreas distintas do remanescente de maior tamanho, uma na região central e duas na área de entorno.

Para obter a taxa de perfilhamento, foi aplicada a metodologia utilizada por Gomes (1992), com algumas adaptações. Nos cálculos, foram utilizados todos os indivíduos amostrados no levantamento fitossociológico, sendo considerados perfilhados os indivíduos que apresentaram mais de um tronco na altura do peito (neste caso cada tronco foi denominado perfilho). Os indivíduos perfilhados foram distribuídos em relação ao número de perfilhos apresentados, com o objetivo de verificar a variação do número de perfilhos por indivíduo e por espécie. Foram calculadas a média de perfilhos por espécie (Mp), através da relação entre o número total de perfilhos de cada espécie $(\mathrm{P})$ e o seu número total de indivíduos (Ni), e a proporção entre indivíduos perfilhados e não perfilhados por espécie (Pip), através da relação entre o número de indivíduos que perfilharam à altura do peito (Ip) e o número total de indivíduos de cada espécie (Ni). Além da taxa de perfilhamento por espécie, também foi obtida a taxa de perfilhamento 
por parcela, desta vez relacionando o número de indivíduos de cada parcela que apresentaram determinado número de perfilhos. Segundo Eiten (1968), o termo deciduidade exprime o grau de retenção foliar dos elementos arbóreos e arbustivos do estrato, ou dos estratos principais encontrados em uma determinada formação em uma determinada época. Para se obter a taxa de deciduidade da formação em estudo, as espécies amostradas no levantamento fitossociológico foram divididas de acordo com a classificação de deciduidade e multiplicadas pelo número de indivíduos de cada espécie presentes no estrato dominante, conforme recomendação de Eiten (1968), de forma a se determinar qual a categoria de deciduidade dominante em toda a comunidade.

O estrato dominante foi definido como aquele formado pelos indivíduos com PAP $\geq 20 \mathrm{~cm}$, amostrados no levantamento fitossociológico. A utilização de todos os indivíduos amostrados (PAP $\geq 15 \mathrm{~cm}$ ) não apresentou alterações significativas no resultado.

As classificações de deciduidade das espécies do estrato dominante foram realizadas através de observações de campo e de citações bibliográficas. As observações de campo foram realizadas durante o período seco e mostraram-se essenciais para a classificação das espécies, já que muitas das citadas em bibliografias como semidecíduas apresentaram-se completamente decíduas na área de estudo.

As espécies foram agrupadas em decíduas e não decíduas, sendo que as espécies desta última categoria foram subdivididas em semidecíduas, perenes, áfilas e plantas que perdem a turgescência foliar. Como semidecíduas, foram definidas as espécies cujos indivíduos apresentaram a copa parcialmente sem folhas no período seco (mais de 10\% da copa sem folhas).

Eiten (1968) considera que plantas áfilas não possuem aparentemente folhas visíveis em nenhum período e que seus troncos são órgãos fotossintéticos. Portanto, devem ser consideradas perenes se nem as touceiras nem os ramos isolados ou outras formas de ramos são desprendidos periodicamente. No caso deste trabalho, independente do desprendimento de ramos, as plantas sem folhas foram consideradas uma subcategoria à parte.

As espécies que apresentam perda de turgescência foliar também foram consideradas uma subcategoria em separado neste trabalho. Isto porque pode-se comprovar, em visitas ao campo durante o período seco, que tais espécies mantêm as folhas verdes (com alguns tons avermelhados em Myrtaceae), mas presas aos ramos na posição vertical e com nítida perda de turgescência, indicando severa deficiência hídrica. No início da estação chuvosa, ou mesmo em chuvas ocasionais durante o período seco, tais espécies recuperam a posição ascendente e a turgescência de suas folhas.

\section{Resultados e Discussão}

Levantamento florístico e fisionomia - No levantamento florístico, foram amostradas 42 famílias, 86 gêneros e 110 espécies (tabela 1). Das 110 espécies, duas estão indicadas apenas no nível de gênero, pertencentes às famílias Myrtaceae e Berberidaceae, pois não foi possível coletar material fértil durante o período do levantamento, aliado à falta de bibliografia especializada e à ausência de materiais comparáveis nos herbários do estado de São Paulo.

Ressalta-se, nessa formação, a presença marcante de espécies em todos os estratos que se apresentam com espinhos (23 espécies ou $20,7 \%$ das

Tabela 1. Espécies amostradas em uma floresta estacional decidual em Piracicaba, São Paulo, Brasil. ESA = número de tombo no herbário ESA; Fit = amostrada no levantamento fitossociológico; $\mathrm{Flor}=$ amostrada no levantamento florístico; $\mathrm{Et}=$ estrato: $\mathrm{E}$ - emergente, D - dossel, S - sub-bosque, H - herbácea, Ef - epífita, L - liana, Pa - parasita; Dec = deciduidade no período seco: DE - decídua, SD semidecídua, $\mathrm{P}$ - perene, $\mathrm{PT}$ - perda de turgescência; $\mathrm{Ep}$ = presença de espinhos.

\begin{tabular}{|c|c|c|c|c|c|c|c|c|}
\hline Famílias & Nome Vulgar & ESA & Fit & Flor & Área & Et & DEC & Ep \\
\hline \multicolumn{9}{|l|}{ Espécies } \\
\hline \multicolumn{9}{|l|}{ ACANTHACEAE } \\
\hline Ruellia graecizans Backer & & & - & $\mathrm{x}$ & 1 & $\mathrm{H}$ & - & - \\
\hline \multicolumn{9}{|l|}{ ANACARDIACEAE } \\
\hline Astronium graveolens Jacq. & Guaritá & 14985 & - & $\mathrm{x}$ & 2 & $\mathrm{E}$ & - & - \\
\hline Myracrodruon urundeuva Fr.All. & Aroeira & & $\mathrm{x}$ & $\mathrm{x}$ & 1,2 & E & $\mathrm{DE}$ & - \\
\hline \multicolumn{9}{|l|}{ APOCYNACEAE } \\
\hline Aspidosperma cylindrocarpon Muell. Arg. & Peroba-poca & & $\mathrm{x}$ & $\mathrm{x}$ & 2 & $\mathrm{E}$ & $\mathrm{DE}$ & - \\
\hline Aspidosperma polyneuron Muell. Arg. & Peroba-rosa & & $\mathrm{x}$ & $\mathrm{x}$ & 2 & $\mathrm{E}$ & $\mathrm{DE}$ & - \\
\hline \multicolumn{9}{|l|}{ ARECACEAE } \\
\hline Syagrus romanzoffiana (Cham.) Glassman & Jerivá & & $\mathrm{x}$ & $\mathrm{x}$ & 2 & $\mathrm{D}$ & $\mathrm{P}$ & - \\
\hline \multicolumn{9}{|l|}{ ASCLEPIADACEAE } \\
\hline Oxypetalum cf. appendiculatum Mart. \& Zucc. & & & - & $\mathrm{x}$ & - & $\mathrm{L}$ & - & - \\
\hline \multicolumn{9}{|l|}{ ASTERACEAE } \\
\hline Dasyphyllum flagelare (Casar.) Cabr. & $\begin{array}{l}\text { Espinho-de- } \\
\text { agulha-açoite }\end{array}$ & 10928 & - & $\mathrm{x}$ & 1 & $S$ & - & $\mathrm{x}$ \\
\hline
\end{tabular}


(cont.)

\begin{tabular}{|c|c|c|c|c|c|c|c|c|}
\hline Famílias & Nome Vulgar & ESA & Fit & Flor & Área & Et & DEC & Ep \\
\hline Eupatorium maximilianii DC. & Mata-pasto & 10931 & - & $\mathrm{x}$ & 1 & S & - & - \\
\hline \multicolumn{9}{|l|}{ BERBERIDACEAE } \\
\hline Actinosires sp. & & & - & $\mathrm{x}$ & 1 & $\mathrm{~S}$ & - & $\mathrm{x}$ \\
\hline \multicolumn{9}{|l|}{ BIGNONIACEAE } \\
\hline Cuspidaria pterocarpa (Cham.) DC. & Cipó-cruz & & - & $\mathrm{x}$ & 2 & $\mathrm{~L}$ & - & - \\
\hline Lundia obliqua Sonder & & 10930 & - & $\mathrm{x}$ & - & $\mathrm{L}$ & - & - \\
\hline Macfadyena aff. unguis-cati (L.) A.Gentry & & & - & $\mathrm{x}$ & 2 & $\mathrm{~L}$ & - & - \\
\hline Tabebuia roseo-alba (Ridley) Sandwith & Ipê-branco & & $\mathrm{x}$ & - & - & $\mathrm{D}$ & $\mathrm{DE}$ & - \\
\hline \multicolumn{9}{|l|}{ BOMBACACEAE } \\
\hline Chorisia speciosa St.Hil. & Paineira & & $\mathrm{x}$ & $\mathrm{x}$ & 1,2 & $\mathrm{E}$ & $\mathrm{DE}$ & $\mathrm{x}$ \\
\hline Pseudobombax grandiflorum (Cav.) A.Robyns & Imbiruçu & & $\mathrm{x}$ & $\mathrm{x}$ & 2 & $\mathrm{E}$ & $\mathrm{DE}$ & $\mathrm{x}$ \\
\hline \multicolumn{9}{|l|}{ BORAGINACEAE } \\
\hline Patagonula americana $\mathrm{L}$. & Guajuvira & & $\mathrm{x}$ & - & - & $\mathrm{D}$ & $\mathrm{DE}$ & - \\
\hline \multicolumn{9}{|l|}{ BROMELIACEAE } \\
\hline Aechmea nudicaulis (L.) Griseb. & Gravatá & & - & $\mathrm{x}$ & 2 & Ef & - & - \\
\hline Ananas fritzmuelleri Camargo & Gravatá & & - & $\mathrm{x}$ & 2 & $\mathrm{H}$ & - & $\mathrm{x}$ \\
\hline \multicolumn{9}{|l|}{ CACTACEAE } \\
\hline Cereus hildmanianus Schum. & Mandacaru & 12748 & $\mathrm{x}$ & $\mathrm{x}$ & - & $\mathrm{D}$ & - & $\mathrm{x}$ \\
\hline Epiphyllum phyllanthus (L.) Haw. & & 10602 & - & $\mathrm{x}$ & - & Ef & - & - \\
\hline Opuntia monacantha Haw. & & 12747 & - & $\mathrm{x}$ & - & Ef & - & - \\
\hline Pereskia aculeata Mill. & Ora-pro-nobilis & 14737,12749 & - & $\mathrm{x}$ & 2 & $\mathrm{~L}$ & - & $\mathrm{x}$ \\
\hline \multicolumn{9}{|l|}{ CELASTRACEAE } \\
\hline Maytenus aquifolia Mart. & Espinheira-santa & & - & $\mathrm{x}$ & 1,2 & S & - & $\mathrm{x}$ \\
\hline Maytenus robusta Reissek & Coração-de-bugre & & $\mathrm{x}$ & $\mathrm{x}$ & 2 & $\mathrm{D}$ & $\mathrm{P}$ & - \\
\hline \multicolumn{9}{|l|}{ COMBRETACEAE } \\
\hline Combretum fruticosum (Loefl.) Stuntz. & & 25467 & - & $\mathrm{x}$ & 2 & $\mathrm{~L}$ & - & - \\
\hline Terminalia triflora Griseb. & Amarelinho & 14983,14998 & $\mathrm{x}$ & $\mathrm{x}$ & - & $\mathrm{D}$ & $\mathrm{DE}$ & - \\
\hline \multicolumn{9}{|l|}{ CUCURBITACEAE } \\
\hline Momordica charantia L. & $\begin{array}{l}\text { Melão-de-são- } \\
\text { caetano }\end{array}$ & 14738 & - & $\mathrm{x}$ & 2 & $\mathrm{~L}$ & - & - \\
\hline \multicolumn{9}{|l|}{ EBENACEAE } \\
\hline Dyospyros inconstans Jacq. & $\begin{array}{l}\text { Fruta-de-jacu- } \\
\text { macho }\end{array}$ & & $x$ & $\mathrm{x}$ & - & $\mathrm{D}$ & $\mathrm{P}$ & - \\
\hline \multicolumn{9}{|l|}{ ERYTHROXYLACEAE } \\
\hline Erythroxylum ambiguum Peyr & & 14694 & $\mathrm{X}$ & $\mathrm{x}$ & - & S & $\mathrm{SD}$ & - \\
\hline \multicolumn{9}{|l|}{ EUPHORBIACEAE } \\
\hline Actinostemon concolor (Spreng.) M.Arg. & $\begin{array}{l}\text { Laranjeira-do- } \\
\text { mato }\end{array}$ & & $\mathrm{x}$ & $\mathrm{x}$ & 2 & $\mathrm{~S}$ & $\mathrm{SD}$ & - \\
\hline Actinostemon klotzchii (Didr.) Pax & & 14740 & $\mathrm{x}$ & $\mathrm{x}$ & - & S & $\mathrm{SD}$ & - \\
\hline Croton salutaris Casar. & Sangue-de-drago & & - & $\mathrm{x}$ & 1 & $\mathrm{D}$ & - & - \\
\hline Sebastiania brasiliensis Spreng. & Tajuvinha & $\begin{array}{l}8448,15003, \\
15002\end{array}$ & $\mathrm{x}$ & $x$ & 1,2 & $\mathrm{D}$ & $\mathrm{DE}$ & $\mathrm{x}$ \\
\hline Sebastiania serrata (Baill.) Muell.Arg. & Branquilho & 8447 & $\mathrm{x}$ & $\mathrm{x}$ & - & $\mathrm{D}$ & $\mathrm{DE}$ & $\mathrm{x}$ \\
\hline \multicolumn{9}{|l|}{ LEGUMINOSAE - CAESALPINOIDEAE } \\
\hline Bauhinia bongardii Steud & Pata-de-vaca & & $\mathrm{x}$ & $\mathrm{x}$ & 1,2 & S & $\mathrm{DE}$ & - \\
\hline Bauhinia cf. microstachya (Raddi) Macbr. & Escada-de-macaco & 14703,14704 & - & $\mathrm{x}$ & - & $\mathrm{L}$ & - & - \\
\hline Cassia patelaria DC. & & 10603 & - & $\mathrm{x}$ & 1 & S & - & - \\
\hline
\end{tabular}


(cont.)

\begin{tabular}{|c|c|c|c|c|c|c|c|c|}
\hline Famílias & Nome Vulgar & ESA & Fit & Flor & Área & Et & DEC & Ep \\
\hline Copaifera langsdorffii Desf. & Copaíba & & - & $\mathrm{x}$ & 2 & $\mathrm{E}$ & - & - \\
\hline Peltophorum dubium (Spreng.) Taubert & Embira-puitá & 14986 & - & $\mathrm{x}$ & 1 & $\mathrm{D}$ & - & - \\
\hline Sweetia frutescens Tul. & $\begin{array}{l}\text { Amendoim-do- } \\
\text { campo }\end{array}$ & & - & $\mathrm{x}$ & - & $\mathrm{D}$ & - & - \\
\hline Senna multijuga (Rich.) I. \& B. & Cássia & 14982,14984 & $\mathrm{x}$ & $\mathrm{x}$ & 1,2 & $\mathrm{D}$ & $\mathrm{DE}$ & - \\
\hline Senna silvestris (Vell.) I. \& B. & & 10597 & - & $\mathrm{x}$ & 2 & $\mathrm{D}$ & - & - \\
\hline Senna splendida (Vog.) I. \& B. & & 14739 & - & $\mathrm{x}$ & 2 & S & - & - \\
\hline \multicolumn{9}{|l|}{ LEGUMINOSAE - FABOIDEAE } \\
\hline Dalbergia frutescens (Vell.) Brith. & & 23140 & - & $\mathrm{x}$ & 2 & $\mathrm{~L}$ & - & - \\
\hline Machaerium hirtum (Vell.) Stellfeld & $\begin{array}{l}\text { Bico-de-pato- } \\
\text { d'espinho }\end{array}$ & & $\mathrm{x}$ & $\mathrm{x}$ & 1,2 & $\mathrm{E}$ & $\mathrm{DE}$ & $\mathrm{x}$ \\
\hline Machaerium nyctitans (Vell.) Benth. & Bico-de-pato & & $\mathrm{x}$ & $\mathrm{x}$ & 2 & $\mathrm{E}$ & $\mathrm{DE}$ & $\mathrm{x}$ \\
\hline Machaerium scleroxylon Tul. & Caviuna & & $\mathrm{x}$ & $\mathrm{x}$ & 2 & $\mathrm{E}$ & $\mathrm{DE}$ & - \\
\hline Machaerium stiptatum (DC.) Vog. & Sapuvinha & 14741 & $\mathrm{x}$ & $\mathrm{x}$ & 2 & $\mathrm{E}$ & $\mathrm{DE}$ & - \\
\hline Machaerium vestitum Vog. & Sapuvussu & 14742 & $\mathrm{x}$ & $\mathrm{x}$ & 2 & $\mathrm{E}$ & $\mathrm{DE}$ & - \\
\hline Machaerium villosum Vog. & Jacarandá-paulista & & - & $\mathrm{x}$ & 2 & $\mathrm{E}$ & - & - \\
\hline Myroxylon peruiferum L.f. & Cabreúva & & $\mathrm{x}$ & $\mathrm{x}$ & - & $\mathrm{E}$ & $\mathrm{DE}$ & - \\
\hline Sweetia fruticosa Spreng. & Sucupira-amarela & & $\mathrm{x}$ & $\mathrm{x}$ & - & $\mathrm{D}$ & $\mathrm{DE}$ & - \\
\hline \multicolumn{9}{|l|}{ LEGUMINOSAE - MIMOSOIDEAE } \\
\hline Acacia polyphylla DC. & Monjoleiro & 14743 & - & $\mathrm{x}$ & 1 & $\mathrm{D}$ & - & $\mathrm{x}$ \\
\hline $\begin{array}{l}\text { Anadenanthera colubrina var. colubrina (Vell.) } \\
\text { Brenan }\end{array}$ & Angico-branco & & - & $\mathrm{x}$ & 1 & $\mathrm{E}$ & - & - \\
\hline $\begin{array}{l}\text { Anadenanthera colubrina var. cebil (Griseb.) } \\
\text { Altschul }\end{array}$ & Angico-vermelho & 15000 & - & $\mathrm{x}$ & 1 & $\mathrm{E}$ & - & - \\
\hline $\begin{array}{l}\text { Parapiptadenia rigida (Benth.) Brenan } \\
\text { LORANTHACEAE }\end{array}$ & Angico-vermelho & 14744,14745 & $\mathrm{x}$ & $\mathrm{x}$ & 2 & E & $\mathrm{DE}$ & - \\
\hline Phoradendron affine (Pohl. ex DC.) Nutt. & $\begin{array}{l}\text { Erva-de- } \\
\text { passarinho }\end{array}$ & 14989 & - & $\mathrm{x}$ & - & $\mathrm{Pa}$ & - & - \\
\hline \multicolumn{9}{|l|}{ LYTHRACEAE } \\
\hline $\begin{array}{l}\text { Lafoensia pacari St.Hill. } \\
\text { MALPIGHIACEAE }\end{array}$ & \multicolumn{7}{|c|}{ MALPIGHIACEAE } & - \\
\hline Stigmaphyllon lalandianum A.Juss. & & & - & $\mathrm{x}$ & 2 & $\mathrm{~L}$ & - & - \\
\hline \multicolumn{9}{|l|}{ MELIACEAE } \\
\hline Trichilia catigua A.Juss. & Catiguá & 14977,15001 & $\mathrm{x}$ & $\mathrm{x}$ & - & S & PT & - \\
\hline $\begin{array}{l}\text { Trichilia elegans A.Juss. } \\
\text { MORACEAE }\end{array}$ & \multicolumn{7}{|c|}{ MORACEAE } & - \\
\hline \multicolumn{9}{|l|}{ MYRTACEAE } \\
\hline Blepharocalyx salicifolius (HBK) Berg. & & 14619 & - & $\mathrm{x}$ & 2 & S & - & - \\
\hline Calycorectes psidiiflorus (Berg) Sobral & & 15013 & - & $\mathrm{x}$ & 2 & $\mathrm{D}$ & PT & - \\
\hline Eugenia blasthantha (Berg.) Legrand & Cambuí & & $\mathrm{x}$ & $\mathrm{x}$ & - & $\mathrm{D}$ & PT & - \\
\hline Eugenia aff. hyemalis Camb. & & $\begin{array}{l}6019,13888 \\
14618\end{array}$ & - & $\mathrm{x}$ & - & $\mathrm{D}$ & - & - \\
\hline Eugenia florida DC. & & $\begin{array}{l}10334,14747 \\
14922,14999\end{array}$ & $\mathrm{x}$ & $\mathrm{x}$ & 1,2 & $\mathrm{D}$ & PT & - \\
\hline Eugenia mansoi Berg. & & & $\mathrm{x}$ & $\mathrm{x}$ & - & $\mathrm{D}$ & PT & - \\
\hline Eugenia mansoni Berg. & & & $\mathrm{x}$ & $\mathrm{x}$ & - & $\mathrm{D}$ & $\mathrm{PT}$ & - \\
\hline Eugenia pluriflora DC. & & 14980,15013 & $\mathrm{x}$ & $\mathrm{x}$ & 2 & $\mathrm{D}$ & PT & - \\
\hline
\end{tabular}


(cont.)

\begin{tabular}{|c|c|c|c|c|c|c|c|c|}
\hline Famílias & Nome Vulgar & ESA & Fit & Flor & Área & Et & $\mathrm{DEC}$ & Ep \\
\hline Eugenia repanda Berg. & & 12750 & - & $\mathrm{x}$ & 2 & $\mathrm{D}$ & PT & - \\
\hline Eugenia aff. sulcata Spring. ex Mart. & & & - & $\mathrm{x}$ & 2 & $\mathrm{D}$ & PT & - \\
\hline Eugenia uniflora $\mathrm{L}$. & Pitanga & $15013 ?$ & $\mathrm{x}$ & $\mathrm{x}$ & - & $\mathrm{D}$ & $\mathrm{DE}$ & - \\
\hline Myrcia ramulosa DC. & & 12756,14979 & - & $\mathrm{x}$ & 2 & S & - & - \\
\hline Myrcianthes pungens (Berg.) Legrand & & & $\mathrm{x}$ & $\mathrm{x}$ & - & $\mathrm{D}$ & $\mathrm{DE}$ & - \\
\hline Myrciaria delicatula (DC.) O. Berg. & & 14617 & $\mathrm{x}$ & $\mathrm{x}$ & - & $\mathrm{D}$ & PT & - \\
\hline Myrciaria sp. & & & $\mathrm{x}$ & $\mathrm{x}$ & - & $\mathrm{D}$ & PT & - \\
\hline \multicolumn{9}{|l|}{ NYCTAGINACEAE } \\
\hline Guapira opposita Reitz. & Maria-mole & 15012 & - & $\mathrm{x}$ & 2 & $\mathrm{~S}$ & - & - \\
\hline \multicolumn{9}{|l|}{ ORCHIDACEAE } \\
\hline Oeceoclades maculata (Lindley) Lindley & & & - & $\mathrm{x}$ & 2 & $\mathrm{H}$ & - & - \\
\hline Rodriguesia decora (Lem.) Rehb.f. & & & - & $\mathrm{x}$ & 2 & Ef & - & - \\
\hline \multicolumn{9}{|l|}{ POLYGALACEAE } \\
\hline Bredemeyera floribunda Willd. & & 10932 & - & $\mathrm{x}$ & 2 & $\mathrm{~L}$ & - & - \\
\hline \multicolumn{9}{|l|}{ POLYGONACEAE } \\
\hline Coccoloba cordifolia Meissner & & $\begin{array}{l}8449,12757 \\
14705\end{array}$ & $\mathrm{x}$ & $\mathrm{x}$ & 1,2 & $\mathrm{D}$ & $\mathrm{DE}$ & - \\
\hline Ruprechtia laxiflora Meissner & Falso-triplaris & & $\mathrm{x}$ & $\mathrm{x}$ & - & $\mathrm{D}$ & $\mathrm{DE}$ & - \\
\hline \multicolumn{9}{|l|}{ POLYPODIACEAE } \\
\hline Microgramma lindbergii (Mett.) Sota & & 25910 & - & $\mathrm{x}$ & 2 & Ef & - & - \\
\hline \multicolumn{9}{|l|}{ PTERIDACEAE } \\
\hline Hemionitis tomentosa (Lam.) Raddi & & 25907 & - & $\mathrm{x}$ & 2 & $\mathrm{H}$ & - & - \\
\hline Doriopteris concolor (Langsd. \& Fisch.) Kuhn. & & 25908 & - & $\mathrm{x}$ & 3 & $\mathrm{H}$ & - & - \\
\hline \multicolumn{9}{|l|}{ RHAMNACEAE } \\
\hline Gouania virgata Reissek & & 10599 & - & $\mathrm{x}$ & 1 & $\mathrm{~L}$ & - & - \\
\hline \multicolumn{9}{|l|}{ RUBIACEAE } \\
\hline Guettarda uruguensis Cham. \& Schlecht. & & $\begin{array}{l}14706,14707, \\
10598,12754\end{array}$ & $\mathrm{x}$ & $\mathrm{x}$ & 2 & $\mathrm{~S}$ & $\mathrm{DE}$ & $\mathrm{x}$ \\
\hline Mannetia ignita Schum. & $\begin{array}{l}\text { Cipó-de-Santo- } \\
\text { Antônio }\end{array}$ & & - & $\mathrm{x}$ & 2 & $\mathrm{H}$ & - & - \\
\hline Randia armata (Sw.) DC. & Sol-de-mata & 14995 & $\mathrm{x}$ & $\mathrm{x}$ & - & S & $\mathrm{DE}$ & $\mathrm{x}$ \\
\hline Simira sampaioana (Standl.) Steyerm. & & 14996 & $\mathrm{x}$ & $\mathrm{x}$ & - & $\mathrm{D}$ & $\mathrm{DE}$ & - \\
\hline \multicolumn{9}{|l|}{ RUTACEAE } \\
\hline Angostura pentandra (St.Hil.) Albuquerque & Angostura & & - & - & - & S & - & - \\
\hline Esenbeckia febrifuga A.Juss. & Mamoninha & 12753,14748 & $\mathrm{x}$ & $\mathrm{x}$ & 1,2 & $\mathrm{~S}$ & $\mathrm{DE}$ & - \\
\hline Metrodorea nigra St.Hil. & Chupa-ferro & 14749 & $\mathrm{x}$ & $\mathrm{x}$ & - & $\mathrm{S}$ & PT & - \\
\hline Pilocarpus pauciflorus St.Hil. & Jaborandi & $\begin{array}{l}14700,14750, \\
14994\end{array}$ & $\mathrm{x}$ & $\mathrm{x}$ & - & $\mathrm{D}$ & $\mathrm{DE}$ & $\mathrm{x}$ \\
\hline Zanthoxylum chiloperone Mart. & Mamica-de-porca & 14751 & $\mathrm{x}$ & $\mathrm{x}$ & 1 & $\mathrm{D}$ & $\mathrm{DE}$ & $\mathrm{x}$ \\
\hline Zanthoxylum hiemale A.St.Hil. & Mamica-de-porca & 14990 & $\mathrm{x}$ & $\mathrm{x}$ & 1 & $\mathrm{D}$ & $\mathrm{DE}$ & $\mathrm{x}$ \\
\hline Zanthoxylum rhoifolium Lam. & Mamica-de-porca & & - & $\mathrm{x}$ & 1 & $\mathrm{D}$ & - & $\mathrm{x}$ \\
\hline \multicolumn{9}{|l|}{ SAPINDACEAE } \\
\hline Diatenopteryx sorbifolia Radlk. & Maria-preta & 14752 & $\mathrm{x}$ & $\mathrm{x}$ & - & $\mathrm{D}$ & $\mathrm{DE}$ & - \\
\hline Paulinia trigonia Vell. & Cipó-timbó & 10601 & - & $\mathrm{x}$ & - & $\mathrm{L}$ & - & - \\
\hline Serjania fuscifolia Radlk. & & 10600 & - & $\mathrm{x}$ & - & $\mathrm{L}$ & - & - \\
\hline \multicolumn{9}{|l|}{ SAPOTACEAE } \\
\hline Chrysophyllum marginatum (Hook. et Arn.) Radlk. & Maçarandubarana & 14981 & $\mathrm{x}$ & $\mathrm{x}$ & 1,2 & $\mathrm{~S}$ & $\mathrm{DE}$ & - \\
\hline
\end{tabular}


(cont.)

\begin{tabular}{|c|c|c|c|c|c|c|c|c|}
\hline Famílias & Nome Vulgar & ESA & Fit & Flor & Área & Et & DEC & Ep \\
\hline \multicolumn{9}{|l|}{ SCHYZAEACEAE } \\
\hline Anemia wettsteinii Christ & & & - & $\mathrm{x}$ & 2 & $\mathrm{H}$ & - & - \\
\hline \multicolumn{9}{|l|}{ SOLANACEAE } \\
\hline Solanum paniculatum $\mathrm{L}$. & $\begin{array}{l}\text { Jurubeba- } \\
\text { verdadeira }\end{array}$ & 10929 & - & $\mathrm{x}$ & 1 & $\mathrm{~S}$ & - & $\mathrm{x}$ \\
\hline \multicolumn{9}{|l|}{ TILIACEAE } \\
\hline $\begin{array}{l}\text { Luehea divaricata Mart. } \\
\text { ULMACEAE }\end{array}$ & Açoita-cavalo & 12755,15011 & $\mathrm{x}$ & $\mathrm{x}$ & 1,2 & $\mathrm{D}$ & $\mathrm{DE}$ & - \\
\hline Celtis iguanea (Jacq.) Sargent. & Espora-de-galo & 10604 & - & $\mathrm{x}$ & 1 & $\mathrm{~S}$ & - & $\mathrm{x}$ \\
\hline \multicolumn{9}{|l|}{ VERBENACEAE } \\
\hline Aloysia virgata Juss. & Licheira & 14702,14988 & - & $\mathrm{x}$ & 1,2 & $\mathrm{~S}$ & - & - \\
\hline Petrea volubilis Jacq. & $\begin{array}{l}\text { Flor-de-São } \\
\text { Miguel }\end{array}$ & 14701 & - & $\mathrm{x}$ & 2 & $\mathrm{~L}$ & - & - \\
\hline $\begin{array}{l}\text { Vitex montevidensis Cham. } \\
\text { VIOLACEAE }\end{array}$ & Tarumã & 14987 & $\mathrm{x}$ & $\mathrm{x}$ & - & $\mathrm{D}$ & $\mathrm{DE}$ & - \\
\hline Hybanthus artropurpureus (St.Hil.) Taub. & & 14991 & - & $\mathrm{x}$ & 1 & $\mathrm{H}$ & - & - \\
\hline
\end{tabular}

espécies amostradas no levantamento florístico tabela 1). Dentre estas, destacam-se, pela sua abundância e agressividade, Cereus hildmanianus, Ananas fritzmuelleri e Aechmea distichantha.

Cereus hildmanianus (mandacaru) é um elemento que se destaca na fisionomia dessa formação, atingindo porte elevado (até $12 \mathrm{~m}$ de altura e $106 \mathrm{~cm}$ de diâmetro a altura do peito) e alta freqüência.

Ananas fritzmuelleri (caraguatá) é uma bromeliácea terrícola extremamente agressiva, chegando a atingir até $1,5 \mathrm{~m}$ de altura e ocupando grandes áreas contínuas no interior do remanescente, dificultando inclusive o deslocamento pelo interior da floresta. Esta bromeliácea não é comum na região. Segundo Reitz (1983), trata-se de espécie bastante rara em estado nativo em Santa Catarina, onde forma pequenos agrupamentos densos e descontínuos, somente nos solos brejosos ou depressões dos terrenos das florestas das planícies litorâneas e da restinga. $\mathrm{Na}$ área de estudo, esta espécie recobre grande parte do solo, estando ausente apenas onde o relevo local apresenta murunduns e canais superficiais não interligados, por onde a água circula no período chuvoso.

Aechmea distichantha ocorre como epífita e mais freqüentemente como terrestre, dividindo as mesmas áreas ocupadas por Ananas fritzmuelleri, chegando a atingir até $1,0 \mathrm{~m}$ de altura. Segundo Reitz (1983), esta espécie se desenvolve como epífita, fixando-se preferencialmente nos galhos e mais raramente sobre os troncos das árvores. Já como terrícola ou rupestre, é encontrada na restinga arbustiva do estado de Santa Catarina, onde por vezes forma densos agrupamentos descontínuos.

Além de Aechmea distichantha, são observadas outras epífitas, principalmente das famílias Orchidaceae (Rodriguesia decora) e Cactaceae (Pereskia aculeata e Rhipsalis elliptica).

Em relação aos demais estratos, o remanescente florestal de 10 ha apresenta dois trechos bem distintos: a região central e a área de entorno. No trecho central, com aproximadamente 1 ha, o dossel varia de 6-12 $\mathrm{m}$ de altura e as árvores emergentes atingem até $20 \mathrm{~m}$, destacando-se de toda a região de entorno. $\mathrm{Na}$ área de entorno, a floresta apresenta dossel descontínuo, com o estrato superior variando entre 4$8 \mathrm{~m}$ de altura e presença de árvores de até $12 \mathrm{~m}$. Para melhor diferenciação destas áreas, foram elaborados diagramas de perfil na região central e nas áreas de entorno (figura 1).

O trecho central da floresta possui composição florística e fisionomia semelhantes à encontrada nos remanescentes de floresta estacional semidecidual da região (figura 1A). Neste trecho, a floresta apresenta o dossel distintamente mais alto e a caducidade dos indivíduos existentes no local ocorre de maneira menos pronunciada e mais tardiamente do que a da 

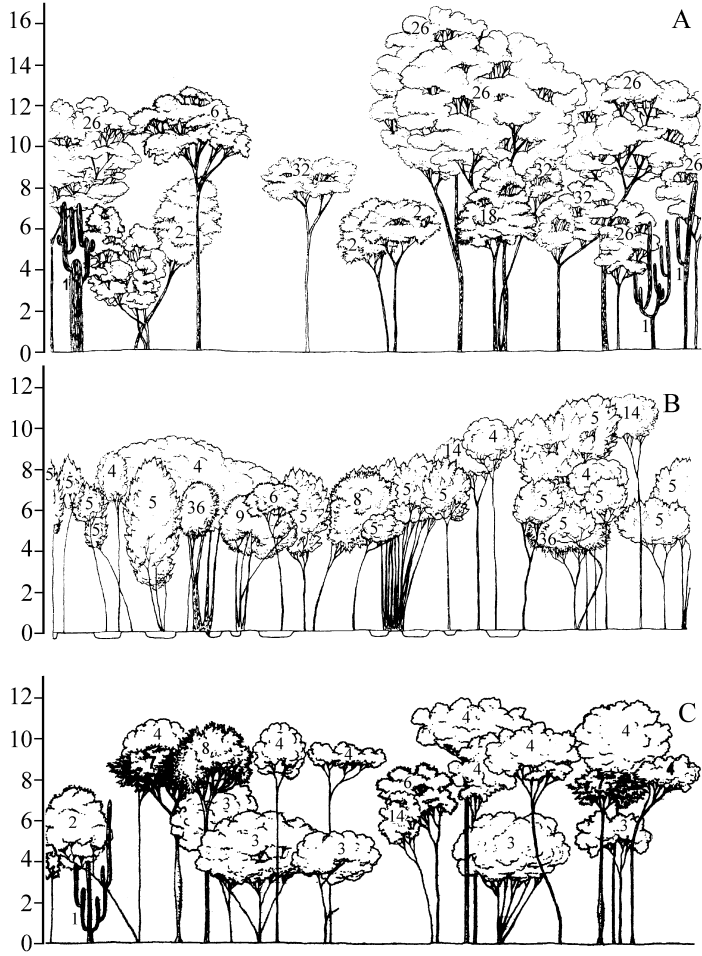

Figura 1. Diagramas de perfil de uma floresta estacional decidual em Piracicaba, São Paulo, Brasil. A. Trecho central; B e C. Áreas de entorno. Os números em cada indivíduo correspondem àqueles das espécies na tabela 4 . Na base do perfil B estão representados canais.

região de entorno. Não há a formação de murunduns e canais superficiais, indicando a ausência de encharcamento. Possivelmente, trata-se de uma área onde o solo, apesar de ainda litólico, apresenta-se mais elevado e profundo em relação à região de entorno, devido a condições geomorfológicas regionais. No sub-bosque, destacam-se Esenbeckia febrifuga, Metrodorea nigra e Actinostemon klotzchii. O dossel é formado por indivíduos de Diatenopteryx sorbifolia, Eugenia uniflora, Eugenia pluriflora e Myrcianthes pungens. A presença de indivíduos de grande porte e emergentes de Machaerium scleroxylon, Machaerium vestitum, Myroxylon peruiferum e Aspidosperma polyneuron, que não ocorrem no entorno, caracterizam esse trecho.

Os perfis $\mathrm{B}$ e $\mathrm{C}$ da figura 1 representam a condição fisionômica mais comum do remanescente, onde predomina um solo raso, com a presença de canais superficiais não interligados e sem orientação definida. Estes canais foram representados no perfil $\mathrm{B}$ e não aparecem no perfil $\mathrm{C}$, apenas porque nesta área são mais rasos e largos. No dossel predominam indivíduos de Sebastiania serrata, Sebastiania brasiliensis, Patagonula americana, Terminalia triflora, Luehea divaricata, Eugenia gardneriana, Eugenia cf. ligustrina e Coccoloba cordifolia, entre outros. Entre as emergentes estão Myracrodruon urundeuva, Aspidosperma cylindrocarpon, Chorisia speciosa e Pseudobombax grandiflorum. O estrato herbáceo nesta área é praticamente inexistente, sendo ocupado por algumas marantáceas e gramíneas apenas na época seca. Em alguns trechos, com canais rasos ou mesmo inexistentes, o estrato herbáceo é bastante característico, dominado por bromeliáceas como gravatás (Ananas fritzmuellleri) e Aechmea disticantha.

Apesar das diferenças nos métodos empregados (tabela 2), a floresta analisada apresentou baixa similaridade florística com os remanescentes de floresta estacional semidecidual do próprio município de Piracicaba (Catharino 1989, Costa \& Mantovani

Tabela 2. Levantamentos florísticos e fitossociológicos utilizados na comparação florística entre áreas de floresta estacional semidecidual do estado de São Paulo e a floresta estacional decidual presente em Piracicaba, São Paulo, Brasil. P = levantamento fitossociológico em parcelas; $\mathrm{F}=$ levantamento florístico; $\mathrm{C}=$ levantamento fitossociológico através de censo; $\mathrm{Q}=$ levantamento fitossociológico por quadrantes; DAP = diâmetro à altura do peito $(1,3 \mathrm{~m})$.

\begin{tabular}{llclc}
\hline Autores & Localidade & Método & Critério de inclusão & Número de espécies \\
\hline Este trabalho & Piracicaba & P & DAP $\geq 4,8 \mathrm{~cm}$ & 54 \\
Catharino 1989 & Piracicaba & P & DAP $\geq 4,8 \mathrm{~cm}$ & 72 \\
Costa \& Mantovani 1993 & Piracicaba & F & DAP $\geq 1,6 \mathrm{~cm}$ & 103 \\
Custódio Filho et al. 1994 & Piracicaba & P & DAP $\geq 10 \mathrm{~cm}$ & 110 \\
Matthes et al. 1988 & Campinas & C & DAP $\geq 10 \mathrm{~cm}$ & 178 \\
Pagano et al. 1987 & Rio Claro & Q & Altura do fuste $\geq 1,3 \mathrm{~m}$ & 191 \\
\hline
\end{tabular}


1993, Custódio-Filho et al. 1994), destacada por um índice de Jaccard de aproximadamente 13\% de similaridade. $\mathrm{O}$ índice também se manteve baixo na comparação com fragmentos de floresta estacional semidecidual localizados em municípios vizinhos como Rio Claro (Pagano et al. 1987) e Campinas (Matthes et al. 1988), com respectivamente 10 e $11 \%$ de similaridade.

Deciduidade - No período seco, o estrato dominante da floresta apresentou $59,4 \%$ de espécies decíduas e $49,6 \%$ não decíduas. Entre as não decíduas, $1,0 \%$ foi classificada como semidecídua e 1,6\% como perenes. Além disso, os indivíduos de Cereus hildmanianus foram considerados áfilos $(13,3 \%) \mathrm{e}$ indivíduos de Eugenia florida, E. cf. ligustrina, E. mansoi, E. mansoni, E. pluriflora, E. blastantha, Myrciaria delicatula, Myrcia ramulosa, Metrodorea nigra e Trichilia catigua apresentaram perda de turgescência foliar $(24,7 \%)$.

A predominância de espécies decíduas determinou a classificação do trecho de floresta estudado como floresta estacional decidual, apesar da sua ocorrência em uma região com características muito distintas da região semi-árida, onde predominam essas formações decíduas (Veloso 1992). A deciduidade, neste estudo, é determinada por uma característica edáfica e não climática. A diferença fisionômica desta formação, em relação à dominante na região (floresta estacional semidecidual), é evidente, já que, no período seco, as espécies semidecíduas foram representadas por apenas 1,0\% dos indivíduos que compõem o estrato dominante.

Perfilhamento - Dos 894 indivíduos amostrados, $31,0 \%$ apresentaram perfilhamento (tabela 3 ). A média de perfilhos por espécie (Mp) variou de dois a oito e o número de perfilhos por indivíduo variou de dois a 11 , sendo que a maior parte dos indivíduos perfilhados (102 indivíduos ou 36,8\%) apresentaram dois perfilhos. Esses resultados estão ainda subestimados, já que só foram amostrados os indivíduos perfilhados que apresentaram pelo menos um dos perfilhos com $\mathrm{PAP} \geq 15 \mathrm{~cm}$.

Gomes (1992), estudando uma floresta estacional semidecidual em São Paulo-SP, encontrou, em média, entre 1,1 e 1,9 perfilhos para as espécies amostradas com no mínimo 10 indivíduos e com $P A P \geq 7 \mathrm{~cm}$. No presente estudo, a média seria de 2,4 a 4,7 para as espécies com no mínimo 10 in- divíduos amostrados, valores mais elevados do que os encontrados por Gomes (1992), apesar de ter sido adotado um $P A P \geq 15 \mathrm{~cm}$ para inclusão de indivíduos na amostragem. Isso indica que a floresta estacional decidual analisada pode apresentar maior número de espécies com altas taxas de perfilhamento, quando comparada com as florestas estacionais semideciduais.

A proporção de indivíduos perfilhados por espécie, utilizando todas as espécies amostradas no levantamento fitossociológico, variou de 0,1 a 1,0 (5\% a $100 \%$ de indivíduos perfilhados por espécie) com uma média de $46 \%$ de indivíduos perfilhados por espécie. Quando se consideram apenas as espécies amostradas com no mínimo 10 indivíduos, obtêm-se de 5\% a 79\% de indivíduos perfilhados por espécie, com média de 33\%. Gomes (1992) encontrou entre $6 \%$ a $50 \%$ de indivíduos perfilhados por espécie, com média de $19 \%$.

Entre as espécies que apresentaram altas taxas de perfilhamento, encontram-se Coccoloba cordifolia, Eugenia uniflora, Sebastiania serrata, Patagonula americana, Cereus hildmanianus e Eugenia florida. Outras espécies do dossel e consideradas finais de sucessão, tais como Aspidosperma cylindrocarpon, Aspidosperma polyneuron, Machaerium scleroxylon, Machaerium vestitum e Myracrodruon urundeuva, também apresentaram indivíduos perfilhados. Sendo assim, o perfilhamento não foi restrito a indivíduos de subosque, como observado em outras unidades fitogeográficas (Gomes 1992), e ocorreu nos vários estádios sucessionais.

Em todas as parcelas, ocorreram indivíduos perfilhados, com a taxa de perfilhamento variando de $5,6 \%$ a 58,3\% de indivíduos perfilhados por parcela. Esta variação não foi contínua, não existindo um gradiente de perfilhamento relacionado a maior ou menor profundidade do solo litólico.

Levantamento fitossociológico - Foram amostrados 936 indivíduos (894 vivos e 42 mortos em pé), pertencentes a 25 famílias, 42 gêneros e 54 espécies arbustivo-arbóreas. A densidade total do levantamento foi de 2176,4 $\pm 165,7$ indivíduos.ha ${ }^{-1} \mathrm{e}$ a área basal de $29,7 \pm 5,5 \mathrm{~m}^{2} \cdot$ ha $^{-1}$.

A família de maior riqueza foi Leguminosae (11 espécies), seguida de Myrtaceae (10 espécies) e Rutaceae (cinco espécies) (figura 2). Estas mesmas 
Tabela 3. Espécies que apresentaram perfilhamento, em ordem decrescente de Mp (média de perfilhos por espécie ) em levantamento fitossociológico em uma floresta estacional decidual em Piracicaba, São Paulo, Brasil. Ni = número total de indivíduos; Ip = número de indivíduos que apresentaram perfilhamento; $\mathrm{P}=$ número total de perfilhos; $\mathrm{Mp}=$ média de perfilhos por espécie; $\mathrm{Pip}=$ proporção de indivíduos perfilhados por espécie.

\begin{tabular}{|c|c|c|c|c|c|c|c|c|c|c|c|c|c|c|c|}
\hline \multirow{2}{*}{ Espécies } & \multirow{2}{*}{$\mathrm{Ni}$} & \multirow{2}{*}{ Ip } & \multicolumn{10}{|c|}{ Distribuicão de Indivíduos (Ip) / Número de perfilhos } & \multirow{2}{*}{$\mathrm{P}$} & \multirow{2}{*}{$\begin{array}{c}\mathrm{Mp} \\
(\mathrm{P} / \mathrm{Ni})\end{array}$} & \multirow{2}{*}{$\begin{array}{c}\text { Pip } \\
\text { (Ip/Ni) }\end{array}$} \\
\hline & & & 2 & 3 & 4 & 5 & 6 & 7 & 8 & 9 & 10 & 11 & & & \\
\hline Eugenia uniflora & 136 & 64 & 12 & 13 & 11 & 6 & 9 & 4 & 2 & 4 & 2 & 1 & 302 & 4,72 & 0,47 \\
\hline Sebastiania serrata & 64 & 25 & 6 & 6 & 4 & 4 & 2 & 0 & 2 & 0 & 1 & 0 & 104 & 4,16 & 0,39 \\
\hline Myrcia ramulosa & 11 & 5 & 0 & 1 & 3 & 1 & 0 & 0 & 0 & 0 & 0 & 0 & 20 & 4,00 & 0,45 \\
\hline Eugenia cf. ligustrina & 34 & 17 & 3 & 4 & 7 & 0 & 1 & 1 & 1 & 0 & 0 & 0 & 67 & 3,94 & 0,50 \\
\hline Patagonula americana & 16 & 7 & 2 & 2 & 2 & 0 & 0 & 0 & 1 & 0 & 0 & 0 & 26 & 3,71 & 0,44 \\
\hline Coccoloba cordifolia & 28 & 22 & 9 & 3 & 7 & 0 & 2 & 1 & 0 & 0 & 0 & 0 & 74 & 3,36 & 0,79 \\
\hline Esenbeckia febrifuga & 19 & 5 & 1 & 3 & 1 & 0 & 0 & 0 & 0 & 0 & 0 & 0 & 15 & 3,00 & 0,26 \\
\hline Chorisia speciosa & 18 & 1 & 0 & 1 & 0 & 0 & 0 & 0 & 0 & 0 & 0 & 0 & 3 & 3,00 & 0,06 \\
\hline $\begin{array}{l}\text { Pseudobombax } \\
\text { grandiflorum }\end{array}$ & 62 & 3 & 1 & 1 & 1 & 0 & 0 & 0 & 0 & 0 & 0 & 0 & 9 & 3,00 & 0,05 \\
\hline Cereus hildmanianus & 95 & 30 & 18 & 5 & 5 & 2 & 0 & 0 & 0 & 0 & 0 & 0 & 81 & 2,70 & 0,32 \\
\hline $\begin{array}{l}\text { Myracrodruon } \\
\text { urundeuva }\end{array}$ & 11 & 3 & 1 & 2 & 0 & 0 & 0 & 0 & 0 & 0 & 0 & 0 & 8 & 2,67 & 0,27 \\
\hline Luehea divaricata & 30 & 6 & 3 & 2 & 1 & 0 & 0 & 0 & 0 & 0 & 0 & 0 & 16 & 2,67 & 0,20 \\
\hline Eugenia florida & 189 & 38 & 27 & 6 & 2 & 1 & 2 & 0 & 0 & 0 & 0 & 0 & 97 & 2,55 & 0,20 \\
\hline Eugenia pluriflora & 17 & 4 & 2 & 2 & 0 & 0 & 0 & 0 & 0 & 0 & 0 & 0 & 10 & 2,50 & 0,24 \\
\hline $\begin{array}{l}\text { Aspidosperma } \\
\text { cylindrocarpon }\end{array}$ & 28 & 10 & 6 & 4 & 0 & 0 & 0 & 0 & 0 & 0 & 0 & 0 & 24 & 2,40 & 0,36 \\
\hline $\begin{array}{l}\text { Aspidosperma } \\
\text { polyneuron }\end{array}$ & 9 & 1 & 0 & 0 & 0 & 0 & 1 & 0 & 0 & 0 & 0 & 0 & 6 & 6,00 & 0,11 \\
\hline Senna multijuga & 9 & 4 & 0 & 1 & 3 & 0 & 0 & 0 & 0 & 0 & 0 & 0 & 15 & 3,75 & 0,44 \\
\hline Machaerium vestitum & 8 & 2 & 0 & 1 & 0 & 0 & 1 & 0 & 0 & 0 & 0 & 0 & 9 & 4,50 & 0,25 \\
\hline Terminalia triflora & 8 & 2 & 2 & 0 & 0 & 0 & 0 & 0 & 0 & 0 & 0 & 0 & 4 & 2,00 & 0,25 \\
\hline Trichilia catigua & 7 & 2 & 0 & 2 & 0 & 0 & 0 & 0 & 0 & 0 & 0 & 0 & 6 & 3,00 & 0,29 \\
\hline Actinostemon klotzchii & 7 & 2 & 1 & 1 & 0 & 0 & 0 & 0 & 0 & 0 & 0 & 0 & 5 & 2,50 & 0,29 \\
\hline $\begin{array}{l}\text { Chrysophyllum } \\
\text { marginatum }\end{array}$ & 7 & 3 & 2 & 0 & 1 & 0 & 0 & 0 & 0 & 0 & 0 & 0 & 8 & 2,67 & 0,43 \\
\hline Ruprechtia laxiflora & 5 & 2 & 1 & 0 & 1 & 0 & 0 & 0 & 0 & 0 & 0 & 0 & 6 & 3,00 & 0,40 \\
\hline $\begin{array}{l}\text { Machaerium } \\
\text { scleroxylon }\end{array}$ & 4 & 2 & 1 & 1 & 0 & 0 & 0 & 0 & 0 & 0 & 0 & 0 & 5 & 2,50 & 0,50 \\
\hline Sebastiania brasiliensis & 4 & 3 & 0 & 2 & 1 & 0 & 0 & 0 & 0 & 0 & 0 & 0 & 10 & 3,33 & 0,75 \\
\hline Ficus guaranitica & 4 & 3 & 2 & 1 & 0 & 0 & 0 & 0 & 0 & 0 & 0 & 0 & 7 & 2,33 & 0,75 \\
\hline Bauhinia bongardii & 3 & 1 & 0 & 0 & 0 & 0 & 0 & 0 & 1 & 0 & 0 & 0 & 8 & 8,00 & 0,33 \\
\hline Sweetia fruticosa & 3 & 1 & 0 & 0 & 0 & 1 & 0 & 0 & 0 & 0 & 0 & 0 & 5 & 5,00 & 0,33 \\
\hline Guettarda uruguensis & 3 & 1 & 0 & 1 & 0 & 0 & 0 & 0 & 0 & 0 & 0 & 0 & 3 & 3,00 & 0,33 \\
\hline $\begin{array}{l}\text { Erythroxylum } \\
\text { ambiguum }\end{array}$ & 3 & 3 & 0 & 2 & 1 & 0 & 0 & 0 & 0 & 0 & 0 & 0 & 10 & 3,33 & 1,00 \\
\hline Maytenus robusta & 2 & 1 & 0 & 0 & 0 & 1 & 0 & 0 & 0 & 0 & 0 & 0 & 5 & 5,00 & 0,50 \\
\hline Randia armata & 1 & 1 & 0 & 0 & 0 & 0 & 0 & 1 & 0 & 0 & 0 & 0 & 7 & 7,00 & 1,00 \\
\hline Dyospyros inconstans & 1 & 1 & 0 & 1 & 0 & 0 & 0 & 0 & 0 & 0 & 0 & 0 & 3 & 3,00 & 1,00 \\
\hline Eugenia blastantha & 1 & 1 & 1 & 0 & 0 & 0 & 0 & 0 & 0 & 0 & 0 & 0 & 2 & 2,00 & 1,00 \\
\hline Eugenia mansoi & 1 & 1 & 1 & 0 & 0 & 0 & 0 & 0 & 0 & 0 & 0 & 0 & 2 & 2,00 & 1,00 \\
\hline
\end{tabular}


famílias foram citadas por Leitão-Filho (1987), como de grande riqueza em florestas estacionais do estado de São Paulo.

Observou-se que 10 das 25 famílias perfizeram $93,85 \%$ do total de indivíduos vivos amostrados. A família mais numerosa foi Myrtaceae, somando 44,07\% do total de indivíduos, cujo destaque deve-se principalmente a Eugenia florida (189 indivíduos) e Eugenia uniflora (136 indivíduos). Em Euphorbiaceae, a elevada densidade foi definida principalmente por Sebastiania serrata (64 indivíduos).

Cereus hildmanianus foi a única espécie de Cactaceae amostrada no levantamento fitossociológico. Bombacaceae destacou-se pela presença de Chorisia speciosa e Pseudobombax grandiflorum, e Leguminosae devido a Machaerium hirtum, Machaerium vestitum e Machaerium scleroxylon, entre outras de menor importância.

Em nenhum outro levantamento realizado no Estado de São Paulo, as famílias Cactaceae, Bombacaceae e Polygonaceae apresentaram-se em destaque na comunidade florestal, evidenciando novamente a peculiaridade desta formação.

As 10 espécies mais importantes somaram $76,6 \%$ do total de indivíduos amostrados, destacando-se nas primeiras posições Eugenia florida, Eugenia uniflora, Cereus hildmanianus, Sebastiania serrata e Pseudobombax grandiflorum, somando 61,1\% (tabela 4). Do total de espécies, 14 (25,9\%) apresentaram um único indivíduo e cinco $(9,3 \%)$ foram amostradas com dois indivíduos.

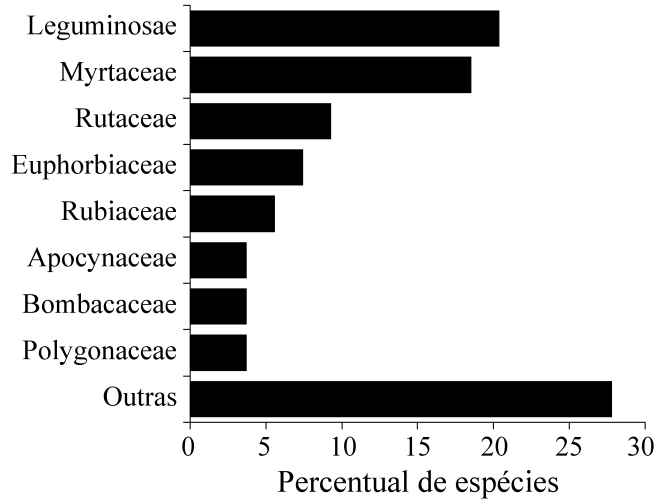

Figura 2. Famílias de maior riqueza em uma floresta estacional decidual em Piracicaba, São Paulo, Brasil.

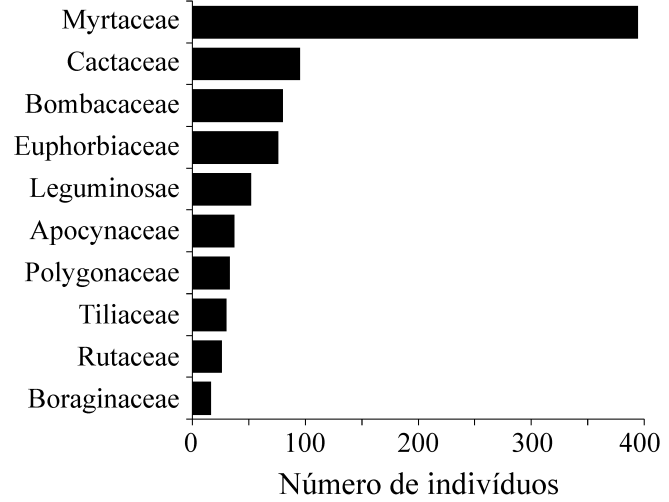

Figura 3. Distribuição do número de indivíduos por família em uma floresta estacional decidual em Piracicaba, São Paulo, Brasil.

As árvores mortas representaram 4,5\% do total de indivíduos amostrados, com valores próximos de dominância $(4,3 \%)$ e com freqüência relativamente elevada $(9,6 \%)$, indicando uma distribuição por toda a área.

As 10 espécies de maior valor de importância (VI) somaram 66,3\% do valor de importância total (tabela 4). Cereus hildmanianus, Pseudobombax grandiflorum e Chorisia speciosa destacaram-se na comunidade devido ao porte elevado dos indivíduos amostrados, que determinam altos valores de dominância. Eugenia florida, Eugenia uniflora, Sebastiania serrata e Eugenia cf. ligustrina destacaram-se pelo elevado número de indivíduos. As demais espécies principais destacaram-se por elevadas dominância e densidade (tabela 4).

Cereus hildmanianus, Eugenia florida e Eugenia uniflora não se destacaram na estrutura de nenhum outro levantamento já realizado em florestas do estado de São Paulo.

$\mathrm{O}$ índice de diversidade de Shannon $\left(\mathrm{H}^{\prime}\right)$ para as 54 espécies da análise fitossociológica foi igual a 3,0 nats/indivíduos e a eqüabilidade $(\mathrm{J})$ foi de 0,7 . O índice de diversidade foi inferior àqueles obtidos para florestas estacionais semideciduais do estado, por exemplo por Rodrigues (1992), amostrando indivíduos com DAP $\geq 5 \mathrm{~cm}$ em 0,8 ha em Ipeúna ( $\mathrm{H}^{\prime}=3,7$ nats/indivíduos); Martins (1993), amostrando 1000 indivíduos com DAS (diâmetro à altura do solo) $\geq 4,8 \mathrm{~cm}$ em 250 pontos em Santa Rita do Passa Quatro ( $\mathrm{H}^{\prime}=3,6$ nats/indivíduos) e Matthes et al. (1988), em um censo dos indivíduos com DAP $\geq$ 
Tabela 4. Parâmetros fitossociológicos das espécies amostradas em uma floresta estacional decidual em Piracicaba, São Paulo, Brasil. $\mathrm{NI}=$ número de indivíduos; FR - frequência relativa $(\%) ; \mathrm{DR}=$ densidade relativa $(\%)$; DOR = Dominância relativa $(\%)$; VI = Valor de importância.

\begin{tabular}{|c|c|c|c|c|c|c|}
\hline & Espécie & NI & FR & $\mathrm{DR}$ & DOR & VI \\
\hline 1 & Cereus hildmanianus & 95 & 8,26 & 10,63 & 25,79 & 44,67 \\
\hline 2 & Eugenia florida & 189 & 11,5 & 21,14 & 7,25 & 39,9 \\
\hline 3 & Eugenia uniflora & 136 & 7,96 & 15,21 & 6,37 & 29,55 \\
\hline 4 & Pseudobombax grandiflorum & 62 & 5,31 & 6,94 & 15,9 & 28,15 \\
\hline 5 & Sebastiania serrata & 64 & 2,65 & 7,16 & 3,58 & 13,39 \\
\hline 6 & Luehea divaricata & 30 & 4,72 & 3,36 & 4,22 & 12,3 \\
\hline 7 & Chorisia speciosa & 18 & 4,13 & 2,01 & 4,95 & 11,1 \\
\hline 8 & Coccoloba cordifolia & 28 & 5,01 & 3,13 & 2,79 & 10,93 \\
\hline 9 & Eugenia cf. ligustrina & 34 & 5,01 & 3,8 & 1,61 & 10,43 \\
\hline 10 & Aspidosperma cylindrocarpon & 28 & 2,65 & 3,13 & 3,77 & 9,56 \\
\hline 11 & Patagonula americana & 16 & 2,95 & 1,79 & 3,44 & 8,18 \\
\hline 12 & Esenbeckia febrifuga & 19 & 2,65 & 2,13 & 0,97 & 5,75 \\
\hline 13 & Eugenia pluriflora & 17 & 2,65 & 1,9 & 0,64 & 5,19 \\
\hline 14 & Machaerium hirtum & 12 & 2,65 & 1,34 & 1,1 & 5,09 \\
\hline 15 & Machaerium vestitum & 8 & 1,18 & 0,89 & 2,51 & 4,59 \\
\hline 16 & Myracrodruon urundeuva & 11 & 2,06 & 1,23 & 1,04 & 4,33 \\
\hline 17 & Ficus guaranitica & 4 & 0,88 & 0,45 & 2,64 & 3,98 \\
\hline 18 & Aspidosperma polyneuron & 9 & 1,77 & 1,01 & 1,15 & 3,93 \\
\hline 19 & Myrcia ramulosa & 11 & 2,06 & 1,23 & 0,52 & 3,82 \\
\hline 20 & Terminalia triflora & 8 & 2,06 & 0,89 & 0,81 & 3,77 \\
\hline 21 & Trichilia catigua & 7 & 2,06 & 0,78 & 0,4 & 3,24 \\
\hline 22 & Senna multijuga & 9 & 0,88 & 1,01 & 1,24 & 3,13 \\
\hline 23 & Parapiptadenia rigida & 7 & 1,47 & 0,78 & 0,65 & 2,91 \\
\hline 24 & Ruprechtia laxiflora & 5 & 1,47 & 0,56 & 0,58 & 2,62 \\
\hline 25 & Actinostemom klotzchii & 7 & 1,47 & 0,78 & 0,24 & 2,5 \\
\hline 26 & Machaerium scleroxylum & 4 & 0,88 & 0,45 & 1,1 & 2,43 \\
\hline 27 & Anadenanthera colubrina & 2 & 0,59 & 0,22 & 1,56 & 2,38 \\
\hline 28 & Crysophyllum marginatum & 7 & 1,18 & 0,78 & 0,29 & 2,25 \\
\hline 29 & Sebastiania brasiliensis & 4 & 1,18 & 0,45 & 0,11 & 1,73 \\
\hline 30 & Bauhinia bongardii & 3 & 0,88 & 0,34 & 0,32 & 1,54 \\
\hline 31 & Sweetia fruticosa & 3 & 0,88 & 0,34 & 0,1 & 1,32 \\
\hline 32 & Myroxylon peruiferum & 2 & 0,59 & 0,22 & 0,42 & 1,24 \\
\hline 33 & Chomelia pohlii & 3 & 0,59 & 0,34 & 0,23 & 1,16 \\
\hline 34 & Erythroxylum ambiguum & 3 & 0,59 & 0,34 & 0,21 & 1,14 \\
\hline 35 & Pillocarpus pauciflorus & 3 & 0,59 & 0,34 & 0,06 & 0,98 \\
\hline 36 & Myrciaria delicatula & 3 & 0,59 & 0,34 & 0,05 & 0,98 \\
\hline 37 & Maytenus robusta & 2 & 0,59 & 0,22 & 0,09 & 0,9 \\
\hline 38 & Zanthoxylum chiloperone & 2 & 0,59 & 0,22 & 0,07 & 0,88 \\
\hline 39 & Diatenopteryx sorbifolia & 3 & 0,29 & 0,34 & 0,14 & 0,77 \\
\hline
\end{tabular}


(cont.)

\begin{tabular}{lllllll}
\hline & Espécie & NI & FR & DR & DOR & VI \\
\hline 40 & Machaerium nictitans & 1 & 0,29 & 0,11 & 0,3 & 0,7 \\
41 & Dyospyros inconstans & 1 & 0,29 & 0,11 & 0,18 & 0,59 \\
42 & Simira sampaioana & 2 & 0,29 & 0,22 & 0,05 & 0,56 \\
43 & Syagrus romanzoffiana & 1 & 0,29 & 0,11 & 0,14 & 0,54 \\
44 & Machaerium stiptatum & 1 & 0,29 & 0,11 & 0,12 & 0,53 \\
45 & Randia armata & 1 & 0,29 & 0,11 & 0,05 & 0,46 \\
46 & Vitex megapotamica & 1 & 0,29 & 0,11 & 0,04 & 0,45 \\
47 & Eugenia mansoi & 1 & 0,29 & 0,11 & 0,04 & 0,45 \\
48 & Eugenia blastantha & 1 & 0,29 & 0,11 & 0,04 & 0,44 \\
49 & Lafoensia pacari & 1 & 0,29 & 0,11 & 0,03 & 0,44 \\
50 & Myrcianthes pungens & 1 & 0,29 & 0,11 & 0,03 & 0,44 \\
51 & Eugenia mansoni & 1 & 0,29 & 0,11 & 0,02 & 0,43 \\
52 & Zanthoxylum hiemale & 1 & 0,29 & 0,11 & 0,02 & 0,43 \\
53 & Actinostemon concolor & 1 & 0,29 & 0,11 & 0,02 & 0,43 \\
54 & Metrodorea nigra & 1 & 0,29 & 0,11 & 0,02 & 0,42 \\
\hline
\end{tabular}

$10 \mathrm{~cm}$ em 2,3 ha em Campinas ( $\mathrm{H}^{\prime}=3,7$ nats/indivíduos). $\mathrm{O}$ valor encontrado aproxima-se de 2,5, 2,8 e 2,8 nats/indivíduos, obtidos em florestas paludosas (matas de brejo) do estado, respectivamente por Torres et al. (1994), em um censo dos indivíduos com DAP $\geq 5 \mathrm{~cm}$ em 0,9 ha; Toniato et al. (1998), amostrando indivíduos com DAP $\geq 3,2 \mathrm{~cm}$ em 0,2 ha e Ivanauskas et al. (1997), em um censo dos indivíduos com DAP $\geq 4,8 \mathrm{~cm}$ em 2,0 ha em Itatinga.

Em matas paludosas, a condição de encharcamento permanente do solo constitui-se no principal fator abiótico, selecionando a ocorrência das espécies vegetais, o que resulta em diminuição da diversidade. No caso da formação estudada, além do encharcamento temporário do solo, também ocorre o estresse hídrico na estação seca, atuando na seletividade das espécies.

A unidade fitogeográfica da floresta estacional decidual já foi descrita em vários estados do nordeste brasileiro, no domínio das caatingas. A ocorrência desta formação é referida predominantemente para o nordeste brasileiro, principalmente no vale do rio São Francisco, do sul da Bahia até o Maranhão (Veloso 1992), em condição climática muito distinta do Estado de São Paulo. O termo floresta estacional mesófila decídua também foi usado por Rizzini
(1963) para designar formações florestais do Brasil Central, que se parecem com uma caatinga arbórea na estação seca, dominada pelos gêneros Magonia e Dipteryx, aparecendo em áreas restritas nas proximidades da caatinga, a noroeste de Minas Gerais.

Para a região sudeste e, em especial, para o Estado de São Paulo, foram poucos os trabalhos que registraram a ocorrência da floresta estacional decidual. Esta ocorre no Estado de São Paulo, sempre associada a solos rasos, calcários e cascalhentos, tanto em terras baixas da Depressão Periférica como em morros calcários do Planalto Ocidental (Rodrigues 1999). Em Minas Gerais, essa formação foi estudada por Ivizi \& Araujo (1997) e Oliveira Filho et al. (1998). No Mato Grosso e Mato Grosso do Sul, essa formação também foi citada em alguns trabalhos (Ratter et al.1988, Prado 1991).

A presença nesta formação, de espécies ocorrentes também nas caatingas nordestinas ou nos chacos argentinos, como Anadenanthera colubrina var. cebil, Myracrodruon urundeuva, Machaerium acutifolium, Ruprechtia laxiflora, Cereus hildmenianus, Diatenopteryx sorbifolia e Platypodium elegans, entre as quais várias se destacam em valor de importância, reforçam os comentários de Prado \& Gibbs (1993) de que essas formações secas formavam um continuum no período seco ocor- 
rido no Pleistoceno. De acordo com esses autores, hoje essa formação tem seus núcleos no nordeste brasileiro (caatinga), no sudeste brasileiro em direção ao vale do rio Uruguai (Missões Argentinas) e no noroeste da Argentina e sul da Bolívia (Piemont), em função das características climáticas dessas regiões. Dessa forma, no processo de retração dessas formações florestais secas para as áreas nucleares atuais, sobraram alguns remanescentes de florestas estacionais deciduais, de definição edáfica e não mais climática, cujas características do solo determinaram na vegetação um estresse hídrico de proporções comparáveis ao estresse climático das regiões nucleares.

\section{Referências bibliográficas}

CATHARINO, E.L.M. 1989. Estudos fisionômico-florísticos e fitossociológico em matas residuais secundárias do município de Piracicaba, SP. Dissertação de mestrado, Universidade Estadual de Campinas, Campinas.

COSTA, L.G.S. \& MANTOVANI, W. 1993. Flora arbustivo-arbórea de trecho de mata mesófila semidecídua na Estação Ecológica de Ibicatu, Piracaba (SP). Hoehnea 22:47-59.

CUSTÓDIO-FILHO, A., FRANCO, G.A.D.C., NEGREIROS, O.C., MARIANO, G., GIANOTTI, E. \& DIAS, A.C. 1994 Composição florística do estrato arbóreo da Estação Ecológica de Ibicatu, Piracicaba, SP. Revista do Instituto Florestal de São Paulo 6:99-111.

EITEN, G. 1968. Vegetation forms (a classification of stands of vegetation based on structure, growth form of the component, and vegetative periodicity). Boletim do Instituto de Botânica 4:1-88.

GOMES, E.P.C. 1992. Fitossociologia do componente arbóreo de um trecho de mata em São Paulo, SP. Dissertação de mestrado, Universidade de São Paulo, São Paulo.

IVANAUSKAS, N.M., RODRIGUES, R.R. \& NAVE, A.G. 1997. Aspectos ecológicos de um trecho de floresta de brejo em Itatinga, SP: florística, fitossociologia e seletividade de espécies. Revista Brasileira de Botânica 20:139-153.

IVIZI, L. \& ARAUJO, G.M. 1997. Fenologia de 14 espécies arbóreas de uma floresta estacional decídua no município de Uberlândia, MG. Arquivos de Biologia e Tecnologia 40:883-892.

JOLY, C.A. 1991. Flooding tolerance in tropical trees. In Plant life under oxygen deprivation: ecology, physiology and biochemistry. (M.B. Jackson, D.D.Davies \& H. Lambers, eds.) Academic Publishing, The Hague, p.23-34.

LEITÃO-FILHO, H.F. 1987. Considerações sobre a florística de florestas tropicais e subtropicais do Brasil. Instituto de Pesquisas Florestais 35:41-46.

MARTINS, F.R. 1993. Estrutura de uma floresta mesófila. Ed. Universidade Estadual de Campinas, Campinas.
MATTHES, L.A.F., LEITÃO-FILHO, H.F. \& MARTINS, F.R 1988. Bosque dos Jequitibás (Campinas, SP): composição florística e estrutura fitossociológica do estrato arbóreo. In Anais do V Congresso da Sociedade Botânica de São Paulo. Sociedade Botânica de São Paulo, Rio Claro, p.55-76.

MUELLER-DOMBOIS, D. \& ELLEMBERG, H. 1974. Aims and methods vegetation ecology. Wiley, New York.

OLIVEIRA, J.B. \& PRADO, H. 1989. Carta pedológica semidetalhada do Estado de São Paulo. Folha de Piracicaba, São Paulo, Secretaria de Agricultura.

OLIVEIRA-FILHO, A.T., CURI, N., VILELA, E.A. \& CARVALHO, D.A. 1998. Effects of canopy gaps, topography and soils on the distribution of woody species in a central brasilian deciduous dry forest. Biotropica 30:362-375.

OMETTO, J.C. 1981. Bioclimatologia vegetal. Editora Agronômica Ceres Ltda., São Paulo.

PAGANO, S.N., LEITÃO-FILHO, H.F. \& SHEPHERD, G. 1987. Estudo fitossociológico em mata mesófila semidecídua, no município de Rio Claro, SP. Revista Brasileira de Botânica 10:49-61.

PRADO, D.E. 1991. A critical evolution of the floristic links between chaco and caatingas vegetation in South America. Thesis, University of St. Andrews, Scotland.

PRADO, D.E. \& GIBBS, P.E. 1993. Patterns of species distributions in the dry seasonal forests of south america. Annals of Missouri Botanical Garden 80:902-927.

RATTER, J.A., POTT, A., POTT, V.J., CUNHA, C.N. \& HARIDASAN, M.1988. Observations on woody vegetation types in the Pantanal and at Corumbá, Brazil. Notes from the Royal Botanical Garden Edinburgh 45: 503-525.

REITZ, R. 1983. Bromeliáceas. In Flora ilustrada catarinense (R. Reitz, ed.). Herbário Barbosa Rodrigues, Itajaí, p.1-797.

RICHARDS, P.W. 1964. The tropical rain forest: an ecological study. University Press, Cambridge.

RIZZINI, C.T. 1963. Nota prévia sobre a divisão fitogreográfica do Brasil. Revista Brasileira de Geografia 25:1-64.

RODRIGUES, R.R. 1992. Análise de um remanescente de vegetação natural às margens do rio Passa Cinco, Ipeúna, SP. Tese de doutorado, Universidade Estadual de Campinas, Campinas.

RODRIGUES, R.R. 1999. A vegetação de Piracicaba e municípios de entorno. Circular Técnica IPEF 189:1-20.

SETZER, S. 1966. Atlas climático e ecológico do Estado de São Paulo. Comissão Interestadual da Bacia do Paraná-Uruguai e Centrais Elétricas do Estado de São Paulo, São Paulo.

SHEPHERD, G.J. 1994. FITOPAC: manual do usuário. Departamento de Botânica, Universidade Estadual de Campinas, Campinas.

TONIATO, M.T.Z., LEITÃO-FILHO, H.F. \& RODRIGUES, R.R. 1998. Fitossociologia de um remanescente de floresta higrófila (mata de brejo) em Campinas, SP. Revista Brasileira de Botânica 21:197-210.

TORRES, R.B., MATTHES, L.A.F. \& RODRIGUES, R.R., 1994. Florística e estrutura do componente arbóreo de uma mata de brejo em Campinas, SP. Revista Brasileira de Botânica 17:189-194.

VELOSO, H.P. 1992. Sistema fitogeográfico. In Manual técnico da vegetação brasileira. Série Manuais Técnicos em Geociências, IBGE, v.1, p.8-38.

WHITTAKER, R.H. 1972. Evolution and measurement of species diversity. Taxon 21:213-251. 